\title{
Tempo perdido: o cotidiano invisível na obra de Adam Magyar
}

Victa de Carvalho Pereira da Silva

Universidade Federal do Rio de Janeiro, Rio de Janeiro, Rio de Janeiro, Brasil

\section{Resumo}

No contexto mais recente das miscigenações entre a fotografia, o cinema e o vídeo, as propostas do artista húngaro Adam Magyar voltam-se para o que o artista chama de tempo perdido do cotidiano urbano, este muitas vezes ocultado pelas velocidades e fluxos da vida nas grandes cidades. A partir das séries Urban Flow (2006-2013) e Stainless (2011-2015), este artigo pretende observar as temporalidades emergentes apreendidas através de tecnologias híbridas de captura de imagens, com o objetivo de refletir sobre as múltiplas formas de experimentar o tempo através das imagens do cotidiano na atualidade. O tempo perdido moderno torna-se, no trabalho de Magyar, um tempo paradoxal no qual a imagem deixa de ser o rastro de um espaço percorrido para tornar-se ela mesma expressão do tempo.

\section{Palavras-chave:}

Fotografia. Cotidiano. Tempo.

\section{Introdução}

No ensaio "Tempo e história: crítica do instante e do contínuo" (2005), o filósofo Giorgio Agamben aponta para a supremacia dessas duas características, o instante e o contínuo, em todas as construções sobre o tempo formuladas pelo pensamento ocidental. Em seu diagnóstico crítico dos diferentes modos de conceber o tempo, desde os gregos até a atualidade, a noção de instante apresenta-se como problema central responsável pela manutenção da compreensão do tempo como uma continuidade de instantes pontuais, garantindo assim a sua irreversibilidade. Sob essa perspectiva, o instante é responsável pela impossibilidade de apreendermos ou experimentarmos o tempo, já que toda experiência do instante é inalcançável, estando assim fora do homem (AGAMBEN, 2005). A principal crítica agambeana gira em torno da exteriorização da experiência, ou seja, o fato de que o privilégio do instante no pensamento ocidental tornou a experiência inapreensível ao homem. 
A modernidade, segundo Agamben com a sua fé no progresso, teria apostado no caráter retilíneo e homogêneo do tempo, ultravalorizando a categoria do instante para privilegiar a dimensão de processo, estruturado de acordo com a lógica do antes e do depois (AgAMBEN. 2005). Tal concepção de tempo esvaziada de sentido ${ }^{1}$ representaria o resultado da experiência do trabalho industrial, na qual o processo seria a finalidade em si. A medida que o sentido pertence ao processo como um todo e não a um agora pontual inapreensível, a concepção de um progresso contínuo e infinito traduz-se como o modelo das ciências para a busca do conhecimento, negando ao homem a capacidade de experienciar a própria história.Agamben afirma ainda que a atual condição política, tornada biopolítica, resulta de uma configuração do tempo que tem na ideia de continuidade as suas condições de possibilidade. As noções de continuidade, linearidade e progresso estariam na base dos determinismos que imperaram na modernidade e, portanto, é fundamental recolocar o problema do instante para pensar uma nova concepção de tempo e de experiência na atualidade. É importante ressaltar que, para o autor, os desvios a esse modelo que compreende o tempo e, assim, a história como continuidade, estiveram presentes no pensamento ocidental de diferentes modos, através da gnose, do estoicismo, do pensamento benjaminiano, e da filosofia hedeggeriana. Ou seja, ainda que o Ocidente tenha formulado noções hegemônicas de temporalidade e de história, ancoradas na continuidade e no determinismo, os desvios as essas concepções sempre existiram, e foram responsáveis pelas brechas que hoje permitem que experimentemos a temporalidade de outras formas.

As possibilidades de captura do movimento e os diversos modos de representação do tempo vêm mobilizando a fotografia e o cinema de inúmeras formas, desde o século XIX até os dias de hoje. Em busca de imagens que representam o movimento e o tempo de acordo com os modelos científicos ou em busca de imagens que propóem uma experiência do tempo capaz de descontruir esses modelos, diferentes dispositivos imagéticos vem convocando o nosso olhar de modo a produzir uma tensão entre o que se pode ver e o que já não se pode ver. Se, por um lado, a representação do tempo como um continuun se sobrepôs historicamente

1 Agamben (2005, p. 115) refere-se a essa experiência como uma experiência de tempo morto e, portanto, inexperienciável para o homem. "A experiência do tempo morto e subtraído à experiência, que caracteriza a vida nas grandes cidades modernas e nas fábricas, parece dar crédito à ideia de que o instante pontual em fuga seja o único tempo humano". 
a outras concepções de tempo durante o período moderno, por outro, inúmeras produções fotográficas e cinematográficas foram responsáveis pela multiplicação do tempo em diferentes vetores, complexificando a relação entre o visível e o invisível.

No contexto mais recente da busca por novas formas de representar o tempo estão as propostas do artista húngaro Adam Magyar. Seus trabalhos imagéticos implicam em miscigenações entre a fotografia, o cinema e o vídeo, e voltam-se para o que o artista chama de tempo perdido do cotidiano ${ }^{2}$ urbano das grandes cidades. A partir das séries Urban Flow (2006-2013) e Stainless (2011-2015), este artigo pretende observar as temporalidades emergentes no cotidiano das grandes cidades e suas possibilidades de representação através de tecnologias híbridas de captura de imagens. Partindo do pressuposto de que uma parcela da experiência cotidiana é muitas vezes ocultada pelas rápidas velocidades e pelos fluxos da vida nas grandes cidades, Magyar cria dispositivos capazes de representar esse cotidiano invisível. Nosso objetivo neste artigo é refletir sobre as múltiplas formas de experimentar o tempo através das imagens do cotidiano produzidas por Adam
Magyar, tendo em vista os principais desafios da fotografia em sua relação com as outras mídias na contemporaneidade. Em busca de formas de representação do tempo capazes de evidenciar a sua multiplicidade e a sua variabilidade, os trabalhos de Adam Magyar dirigem-se ao cotidiano urbano como estratégia para produzir seus questionamentos sobre a temporalidade. Sejam filmes ou fotografias nos quais o tempo é muito lento ou oferecem situações de espera muito longa, sejam imagens que obsessivamente nos compelem a uma temporalidade baseada na instabilidade, na fragmentação e nas intermitências, suas propostas rompem com os modelos hegemônicos de visibilidade e inteligibilidade da imagem para através da tensão entre o visível e o invisível nas grandes cidades que nos oferece uma experiência do nosso tempo atual. São trabalhos que investem em imagens estranhas, borradas, disformes, que nos impedem de ver a cena com clareza, mas apostam em uma temporalidade complexa que emerge desta impossibilidade. Quando ver torna-se um ato de perda, o que a imagem pode então nos revelar? Qual seria a experiência do tempo característica da contemporaneidade e quais imagens nos ofereceriam essa experiência? Que relação entre o visível e o 
invisível a fotografia contemporânea em diálogo com outras mídias pode instaurar?

Para Adam Magyar, trata-se de usar a tecnologia mais recente para criar novas formas de captura do tempo através das imagens fixas e das imagens em movimento. O tempo é percebido como um fluxo ininterrupto de instantes quaisquer vivenciados no cotidiano urbano, uma continuidade indivisível que só pode ser percebida por meio de sua presentificação na imagem. A tecnologia apresenta-se como um fator determinante na conquista dessas imagens. É importante ressaltar que a experiência na/da cidade tem sido um lugar privilegiado para compreendermos as transformações na percepção e nas subjetividades, pelo menos desde a modernidade do século XIX, principalmente no que se refere ao impacto das novas tecnologias experimentadas. Sob essa perspectiva, as proposições visuais e audiovisuais de Adam Magyar se constituem como possibilidades de atualização da experiência do tempo por intermédio das imagens do cotidiano urbano, buscando entrever o que nos passa desapercebido, o que não percebemos na nossa experiência cotidiana, através da relação que a fotografia instaura entre a imagem fixa e a imagem em movimento na atualidade.

\section{Cronofotografia e Cinema}

A paisagem urbana do século XIX, organizada segundo a lógica da circulação e da aceleração, é emblemática das mudanças perceptivas $^{3}$ e ambientais que definiram a experiência da modernidade em pelo menos dois aspectos: uma experiência em que o tempo é um agente fundamental como elemento regulador da vida e das distâncias, e uma nova experiência do corpo e da percepção humana, moldada pelas novas velocidades e perigos da vida na cidade. Essa nova experiência do tempo e do corpo refletem-se sobretudo nas imagens da fotografia e do cinema, tecnologias disponíveis e amplamente utilizadas na busca pela representação do cotidia no urbano. Sabemos que a modernidade do século XIX é marcada por uma concepção ambígua do tempo e de seus modos de percepção. Seja como fluxo ou como descontinuidade, a disputa em torno de seu modo de representação mobilizou um conjunto de cientistas e artistas interessados em comprovar suas teorias utilizando o arsenal tecnológico disponível na época. Segundo Doane (2002), na contramão das teorias que anteviam a temporalidade como algo a ser experimentado em forma de um continuun, o desejo moderno de dissecar o tempo, de saber o que acontece

3 Desde o século XIX, diversos autores, entre eles Simmel (2005) e Benjamin (1994), enfatizaram as transformações operadas na percepção humana tendo em vista as novas estimulações sensoriais oferecidas pela turbulenta vida urbana, com seu barulho, suas multidões, sinais de trânsito, vitrines e anúncios. 
na duração entre uma fração de segundo e a fração seguinte, e conhecer aspectos inacessíveis à visão humana, prevaleceu no campo da ciência nas pesquisas dos fisiologistas da visão ${ }^{4}$, empenhados em elucidar uma imagem para o tempo. Entre eles, Étienne-Jules Marey destaca-se por seus experimentos ao recorrer à técnica fotográfica com o objetivo de capturar e medir o tempo de modo objetivo, ainda que o resultado parecesse sempre suprimir a própria possibilidade de representação (DOANE, 2002). Trabalhando no limite do problema da representação, os experimentos de Marey teriam desempenhado papel fundamental não apenas para o desenvolvimento da técnica fotográfica e das suas múltiplas formas de capturar o instante, como também no desenvolvimento do cinema como um modo específico de organizar e regular o tempo.

São conhecidas as pesquisas do fisiologista francês Étienne-Jules Marey e as aproximações entre ciência e fotografia na produção de imagens diretas do movimento impossíveis de serem visualizadas de outra forma. Denominada cronofotografia, sua técnica permitia estudar a correlação entre tempo e espaço enquanto um corpo mudava de posição. Segundo Doane (2002), a obsessão de Marey em medir, capturar, representar o movimento através do tempo é resultado de seu profundo interesse no conceito de "tempo perdido" apresentado pelo cientista alemão Hermann von Helmholtz para abordar o intervalo existente durante o processo de percepção, mais especificamente o intervalo entre o estímulo e a resposta do corpo. Para Marey, era urgente tornar visível esse tempo perdido, e a fotografia parecia ser a técnica ideal para alcançar esse objetivo. ${ }^{5}$

Do ponto de vista histórico, a experiência pioneira da captura do movimento com a técnica fotográfica foi realizada alguns anos antes pelo inglês Eadweard Muybridge ${ }^{6}$, ao registrar momentos imperceptíveis ao olho

4. 0 impacto das fisiologias da visão foi observado por Crary (2012) como fator determinante na constituição de um novo regime de visão no século XVIII, que deixa de se ancorar no modelo da câmera escura, para se estabelecer na materialidade do corpo e nas suas opacidades. Trata-se de observar o processo de modernização da visão em consonância com as mudanças na subjetividade moderna, estas anteriores à invenção da fotografia.

5 As pesquisas iniciais de Marey utilizaram técnicas gráficas para obter imagens diretas do movimento dos corpos no espaço. Segundo Doane (2002), a concepção da fotografia como index foi fundamental para que a fotografia se tornasse a técnica ideal para esses experimentos. A indexicalidade era o grande atributo da clareza da representação, ou seja, sua legibilidade. É importante ressaltar que Marey começa a utilizar a fotografia em 1878, a partir de seu contato com as pesquisas de Muybridge.

6 Seu experimento emblemático (1877-1878) foi o registro do trote do cavalo utilizando 12 câmeras preparadas para capturar uma imagem com menos de 2 centésimos de segundo. Muybridge ligou as câmeras às baterias elétricas que funcionavam como sensores - quando o animal rompia os fios ligados às baterias, acionava as câmeras de modo sucessivo -, criando imagens sucessivas, em diferentes frames, da trajetória do animal. Seu experimento gerou forte » 
humano durante o trote de um cavalo, como demonstram as já reconhecidas publicações da área. Mas são as pesquisas de Marey sobre a dimensão espaço-temporal do movimento que possibilitaram a captura das fases consecutivas do movimento em uma mesma fotografia. Com a técnica do fuzil cronofotográfico (1882), Marey captura as posições sucessivas do objeto em movimento em um mesmo frame. O fuzil capturava 10 imagens por segundo, representando as diferentes posições ocupadas por um corpo ao longo de um deslocamento. Suas pesquisas subsequentes foram impulsionadas pelo desejo de diminuir cada vez mais o intervalo entre essas posições, que resultaram, inevitavelmente, em imagens superpostas e borradas.

No limite da legibilidade da imagem, o trabalho de Marey explicitava o dilema de sua busca por uma representação perfeita do tempo. Quanto menores os intervalos de tempo capturados, menor a legibilidade da imagem, principalmente porque a representação estava limitada a um espaço restrito de um frame retangular, tornando impossível representar o deslocamento sem sobrepor as imagens. Por outro lado, com um número menor de posições, a legibilidade do tempo seria sacrificada. Apesar de seus esforços para capturar o "tempo perdido", a cronofotografia baseava-se em intermitências, de modo que as perdas eram inevitáveis. Apesar de profundamente ancorado no positivismo, o resultado estético destas sobreposições promoveu forte influência entre os pintores impressionistas a exemplo de Edgard Degas e Georges Seurat $^{7}$, e entre os pintores abstratos. Segundo Braum (1992), os trabalhos de Marey foram interpretados de diferentes maneiras pelos artistas de acordo com a visão de cada um sobre a modernidade, incluindo aqueles que rejeitaram fortemente o positivismo.

Em torno das diversas iniciativas de utilização da fotografia para representar o tempo na modernidade, destacamos a experiência do fotodinamismo liderada pelos irmãos Bragaglia no interior do movimento da vanguarda futurista. Em contraposição ao processo analítico desenvolvido pela cronofotografia, Anton Giulio Bragaglia considera o método utilizado por Marey insuficiente e incapaz de traduzir o fluxo do movimento contínuo no tempo. Trata-se para ele de buscar, através de um trabalho de análise e síntese, 
a continuidade do gesto no espaço. Ao comparar a cronofotografia aos ponteiros de um relógio que marca apenas quartos de hora, o fotodinamismo seria um ponteiro capaz de indicar os momentos mínimos entre os segundos. (FABRIS, 2011). Assim, o investimento de Bragaglia na superação dos limites da cronofotografia e da própria pintura futurista, insere a fotografia como técnica ideal para a representação da complexidade do tempo a partir de um movimento no espaço.

É interessante perceber que aquilo que o próprio Marey considerava um limite de seu trabalho - a sobreposição e o borrão - foi assumido pela vanguarda futurista, em particular pelo fotodinamismo, como a perfeita representação do tempo. Nesse contexto, Anton Giulio Bragaglia declarou a insuficiência tanto da cronofotografia e do instantâneo fotográfico, quanto do cinema em traduzir o fluxo contínuo do movimento no tempo. Negligenciando a trajetória, no caso do cinema e da cronofotografia, ou contraindo e imobilizando o movimento em todos os seus estados possíveis, no caso do instantâneo, tais estratégias não criavam a sensação do movimento. No fotodinamismo ${ }^{8}$, a representação do movimento necessariamente destrói a matéria, resultando em distorções e borrões, de modo que a multiplicação do objeto, como realizada pela cronofotografia, seria uma falsa estratégia.

Para além do campo da arte pictórica e da ciência, as experiências de captura e armazenamento do movimento através do tempo foram também protagonizadas pela fotografia de rua, na segunda metade do século XIX. A longa trajetória da fixação do movimento pode ser observada desde a imagem de Charles Nègres, Les ramoneurs de Paris (1851), em que três limpadores de chaminé aparecem congelados enquanto caminham pela cidade, ao passo que a paisagem de fundo surge em movimento, em flou. Podemos imaginar que por conta dos longos tempos de exposição da placa sensível à luz, o fotógrafo tenha demandado aos limpadores de chaminé que posassem para a sua câmera, o que apenas reforça o desejo pela captura do movimento através do instantâneo fotográfico. De modo geral, a captura de cenas da cidade era nesse período feita a partir de longas exposições decorrentes da tecnologia empregada, que resultavam em cenas nas quais os movimentos apareciam na forma de borrões, a exemplo da Le point des arts (1867), de Adolphe Braun, ou mesmo desapareciam da cena como em View of the Boulevard du Temple, de Louis-Jacques-Mandé Daguerre (1838). Segundo André Gunthert 
(1999), a conquista do instantâneo fotográfico denota um campo imaginário que a precede como forma de um desejo e que os modelos icônicos aos quais se referem o termo "instantâneo" evoluem de acordo com as tecnologias disponíveis.

Para Fatorelli (2013, p. 41), a conquista do instante pela fotografia moderna integra uma rede de teorias que compreende o movimento a partir de uma sucessão de instantes estáticos, oferecendo "a falsa impressão de estado temporal em suspensão, destituído de espessura". A ideia de que a fotografia seria capaz de congelar o tempo sustentou a invenção de diferentes tecnologias capazes de produzir imagens com tempos de impressão cada vez menores. Sob essa perspectiva, inscrevem-se as já citadas cronofotografias de Marey e Muybridge e as suas indagações a respeito da representabilidade do tempo a partir do movimento, mas também todo um conjunto de imagens fotográficas que vão buscar no contexto das ruas das cidades o modo de inscrição e de eternização das cenas vividas que escapavam cada vez mais à própria experiência perceptiva do sujeito moderno.

\section{Urban Flow - contínuo do tempo}

Uma parcela significativa dos trabalhos visuais e audiovisuais que hoje ocupam as galerias de arte é marcada por um forte investimento em estratégias que complexificam a nossa relação com o tempo através do cotidiano das cidades. São propostas que miscigenam a fotografia com o cinema, com o vídeo, mas também a performance e as mídias digitais, e nos interrogam sobre as possibilidades de experiência a partir de uma complexa trama de captura, produção e apresentação das imagens. Entre elas, destacamos os trabalhos de Doug Aitken, Kim Sooja, Beat Streuli, Hou Chien Cheng, Gusztáv Hámos, Zhenchen Liu, Rafael Lozano-Hemmer, Giselle Bieguelman, David Rockeby, Chantal Akerman, Cao Guimarães, Gustavo Pelizzon, Lucas Bambozzi, Dirceu Maués. Ainda que o conjunto citado nos pareça bastante heterogêneo, são todos eles artistas que produzem obras híbridas, miscigenadas, que privilegiam na maioria das vezes pessoas em situações rotineiras, sem qualquer acontecimento marcante, e se aproximam do cotidiano de modo a problematizar nossa experiência com as imagens através do tempo, investindo na própria banalidade dos nossos condicionamentos diários. São obras visuais e audiovisuais em que a relação entre tempo e movimento é o personagem que vai promover diferentes questionamentos: sejam em obras nas quais o tempo é problematizado através de movimentos aberrantes, lentíssimos ou acelerados ao extremo; sejam em obras que multiplicam os tempos de modo a torná-los inapreensíveis, paradoxais através de imagens que se sobrepõem em um circuito de indiscernibilidade e irrepresentabilidade. 
Nesse conjunto de obras recentes que problematizam a relação entre o cotidiano e o tempo, inserimos o trabalho do artista experimental Adam Magyar e seu interesse em fotografar e/ ou filmar pessoas pelo mundo em diferentes cidades. Engenheiro e fotógrafo autodidata, Magyar desenvolve os próprios equipamentos e softwares para seus projetos. É significativo que suas imagens sejam obtidas a partir do desenvolvimento de tecnologias específicas de captura - fotografia e vídeo digital - que posteriormente são montadas com a utilização de softwares. Em sua busca pelos momentos banais, não privilegiados do dia a dia, Magyar usa diferentes tecnologias para retratar as pessoas em seus deslocamentos diários: andando na rua, baldeando de trem, ressaltando os momentos que normalmente passam desapercebidos ao longo desses trajetos cotidianos que induzem à distração. Suas imagens híbridas, entre a fotografia, o cinema e o vídeo, tensionam as categorias de tempo e movimento ao limite da própria representabilidade.

Em Urban Flow (Figura 1), Adam Magyar trabalha a partir do desejo de capturar a experiência da cidade contemporânea através da potência das ruas, buscando sempre as novas possibilidades perceptivas oferecidas pelos atuais contextos e pelas mais recentes tecnologias. Sob essa perspectiva, já não se trata de ir às ruas buscar imagens que reflitam de modo objetivo a nossa experiência perceptiva contemporânea a partir da captura do instante, como teriam feito por exemplo os fotógrafos da street photography ${ }^{9}$, mas de buscar outros modos pelos quais o tempo pode ser experienciado na contemporaneidade e quais imagens poderiam dar conta dessa experiência. Sua busca se aproxima das proposições mais experimentais do cinema e do vídeo, a exemplo de Chantal Akerman e Chris Marker, em suas pesquisas sobre o cotidiano urbano e o tempo ${ }^{10}$.

Ao desenvolver uma câmera capaz de capturar uma imagem contínua do tempo, Magyar produz imagens nas quais as pessoas parecem estar em uma caminhada infinita no espaço e no tempo. O equipamento é uma adaptação de um scanner de alta resolução colocado na direção vertical no interior de uma caixa preta. $\mathrm{O}$ artista utiliza a câmera fixada em um

9 Segundo Scott (2009), a street photography é uma tradição que remonta ao início do século XX, e revela o potencial da fotografia como instrumento poético do cotidiano. Com forte ressonância na estética da fotografia documental e da fotografia jornalística, a fotografia de rua conjuga a diversidade, o caos, a velocidade das ruas com um olhar criativo e original sobre as banalidades do dia a dia.

10 Destacamos, para uma futura leitura aproximativa, os trabalhos de Chris Marker - Sans Soleil (1983) - e de Chantal Akerman - D'Est (1983) - que, ao abordarem o cotidiano das cidades, interrogam e complexificam o tempo através das imagens. 
tripé, e captura em apenas uma linha vertical de varredura, uma espécie de frame vertical, o movimento dos passantes na cidade. Através de um software, os pixels capturados são recompostos de forma contínua no espaço, um depois do outro, transformando a captura vertical contínua em espaço contínuo horizontal ${ }^{11}$. O resultado é uma câmera que captura imagens em movimento das pessoas caminhando na rua, mas as imprime dentro de um mesmo frame, construindo assim uma grande imagem panorâmica de uma caminhada contínua que jamais aconteceu.

\section{Figura 1: Urban Flow. Nova York, 2015. 60 x $180 \mathrm{~cm}$}

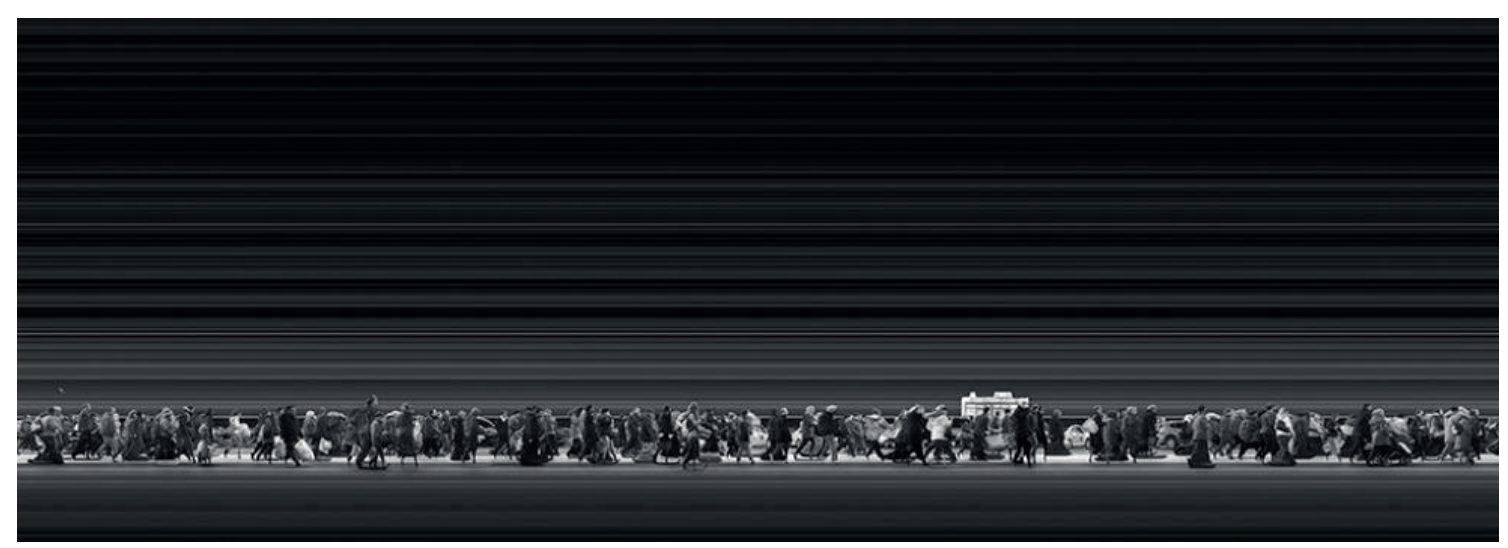

Fonte: Disponível em: <http://www.magyaradam.com/wp/?page_id=511>. Acesso em: 08 abr. 2020.

Os intervalos de tempo e espaço registrados através dessa câmera fotocinemática produzem uma imagem sem ponto de vista, desprovida das regras da Perspectiva Renascentista. A passagem do tempo se torna o espaço, avançando no tempo do lado direito para o lado esquerdo em cada imagem. Como resultado dessa conexão espaço-tempo, todas as pessoas e veículos nas fotos parecem caminhar em uma mesma direção. É marcante nas imagens desta série que o resultado da passagem do tempo transformada em espaço, construa uma imagem que de fato nunca existiu diante de um olho humano, ou seja, uma imagem que pode ser considerada um tipo de montagem na qual as pessoas caminham na mesma direção em um plano de fundo que se caracteriza por uma paisagem da cidade transformada 
em linhas e marcas abstratas. Trata-se de uma importante inversão no modelo da física newtoniana que prevaleceu no campo científico da fisiologia do movimento, na qual o estudo do tempo se dava a partir de um deslocamento no espaço. Trata-se aqui de um processo de temporalização do espaço que toma forma a partir de um tempo em fluxo que se desenrola através de uma série de pontos verticais tornados horizontais na imagem final. Tal operação resulta no contraste entre a desfiguração da paisagem da cidade e a definição dos passantes das ruas.

Ainda como resultado dessa mesma operação fotocinemática, observamos as inúmeras distorções às quais as imagens desses passantes foram submetidas por causa dos procedimentos tecnológicos utilizados. Pernas e pés tomam proporções monstruosas, deformadas e desproporcionais, alongando o intervalo entre um passo e o seguinte. Enfatiza-se a ilusão de uma continuidade, de uma espécie de marcha sem fim, onde o fim parece ser o limite espacial do frame da própria imagem. Os caminhantes dessa marcha fictícia tornam-se monstros absorvidos em seu longo percurso, como zumbis marchando rumo a um único objetivo.

Cabe relembrar que a experiência do sujeito moderno nas grandes cidades estava inevitavelmente ligada aos modos de organização, medição e decomposição do tempo, este observado cientificamente a partir de uma trajetória no espaço. Tal espacialização do tempo é questionada no século XIX pelo filósofo Henri Bergson, para quem o tempo só existe em fluxo, e o instante nada mais é do que uma categoria secundária, ilusória, na qual o pensamento cria uma imagem. Ao converter as características qualitativas do movimento em características quantitativas, a ciência moderna teria, segundo Bergson, tornado o movimento divisível, observável e cognoscível. Tomando o paradoxo de Zenon como exemplo deste equívoco, o movimento para Bergson acontece no intervalo, na transição entre os estados, e não na síntese de instantes fixos. O movimento seria então a realidade em si, contínua mudança, transição, indivisível. Nessa perspectiva, o tempo puro seria composto desses instantes indivisíveis. Seu principal argumento ancorado no conceito de duração se inscrevia claramente contra a rede de experimentos que apostava no instantâneo como método de obtenção de verdadeiro conhecimento. Para Bergson, o movimento não pode ser reduzido a um instante fixo, de modo que os experimentos de Marey representariam exemplos perfeitos para demonstrar o que não seria a realidade.

O pensamento de Henri Bergson apresenta-se como alternativa às teorias do século XIX que privilegiavam a percepção a partir 
da ideia de presença e de imediatismo. O que diversos pensadores e cientistas chamavam de uma percepção pura, para Bergson, era apenas um ideal existente na teoria, e não de fato. No século XIX, tal percepção idealizada poderia ser alcançada a partir de um profundo mergulho no presente que permitiria a visão do imediato e do instantâneo. Era o sonho do imediatismo inumano, de um ato perceptivo primordial e fundamental que revelaria a essência das coisas, uma percepção confinada ao presente. Contrariando tais concepções, Bergson argumenta que toda percepção, não importa o quanto aparentemente instantânea ela seja, constitui-se sempre de uma duração que prolonga o passado no presente, contaminando sua pureza pelas articulações da memória. Para o filósofo, as mais ricas e criativas formas de vida ocorreriam no que ele chama de zona de indeterminação, no curto-circuito entre o estímulo e a resposta, quando a memória entra em cena abrindo a experiência à esfera da virtualidade. Sendo o sujeito um centro de indeterminação em potencial, o autor postula a sua capacidade de sempre recriar o presente.

Ver o tempo, distorcê-lo, rasgá-lo, fazê-lo desaparecer, foi um dos grandes sonhos artísticos do Ocidente, que investiu na fabricação de máquinas de visão e na criação de estratégias que desestabilizassem o regime de centramento postulado pelas leis da perspectiva linear. Tanto para a teoria da arte quanto para os artistas e cineastas dos anos 1970: o frágil, o efêmero, o instável, o transitório, constituíram temas dominantes nas propostas artísticas dessa época ${ }^{12}$. Segundo Buci-Glucksmann (2003), as temporalidades múltiplas, o fluxo complicado do tempo, o tempo do virtual, permanecem como inquietações filosóficas e continuam a fazer parte dos trabalhos de arte hoje. Para a autora, é possível identificar na atualidade uma forte desestabilização de um olhar imóvel em proveito de um olhar flutuante que cartografa o tempo, multiplica-o e projeta-o em um novo contexto audiovisual. (BUCI-GLUCKSMANN. 2003). Sob essa perspectiva, as preocupações com o tempo, a memória e a constituição do visível integram as propostas fotocinemáticas de Adam Magyar, e nos conduzem a uma abertura ao olhar das impossibilidades e das instabilidades tanto da experiência contemporânea na cidade quanto das formas imagéticas. As imagens de Urban Flow denotam um fluxo de tempo, onde os instantes não são a soma das partes, aproximando-se das premissas bergsonianas. São imagens distendidas, imagens que duram ao longo de um movimento aqui representado 
pela caminhada urbana que não se assemelha à realidade, mas tampouco deixa de corresponder ao real.

Se a tecnologia criada por Magyar não visa à construção de uma imagem cientificamente realista, tal qual o desejo da cronofotografia no século XIX, não significa que seu trabalho escape ao desejo por uma imagem que está para além dos limites da percepção humana. Ainda que sua câmera não capture o movimento de modo a congelá-lo e transformá-lo em instantes descontínuos, a principal crítica de Bergson aos experimentos de Marey, seu modo de inscrição do tempo em fluxo instaura-se a partir de uma espacialidade a ele associada. O espaço aqui não é o resultado de um percurso transcorrido ou mesmo visível, pois essa cena jamais ocorreu desse modo. Ao contrário, o espaço de Magyar é criado por um tempo complexo e em fluxo. Suas fotografias não representam instantes fixos, mas seus intervalos contínuos.

As imagens de Magyar já não têm como tarefa oferecer uma informação sobre a cidade, ou dar a ver uma verdade única sobre o contexto urbano, mas nos oferecer uma experiência múltipla do tempo, marcada pelos deslocamentos contínuos, pelas falhas, pelos excessos e pelas intensidades da vida nas ruas. Urban Flow retoma a caminhada como o gesto que vai permitir a representação da experiência imagética da cidade, pois se todo o deslocamento permite a multiplicidade de pontos de vista, ele também permite as pluralidades das velocidades e dos tempos. Trata-se aqui de uma temporalidade complexa alcançada a partir do diálogo entre a imagem estática e a imagem em movimento.

Tal proposição está intimamente associada ao modo como hoje percebemos a miscigenação das práticas de produção visual e audiovisual em um contexto marcado pela multiplicidade de modos de ser da imagem. Para Fatorelli (2013), trata-se de uma operação de multiplicação de vetores temporais, efetuada pelas produções fotográficas pós-modernas, incluindo aí a estrutura das imagens de síntese, que "estabelece um curto-circuito no cerne da suposição ontológica" (p. 47) atrelada aos ideais de imparcialidade e objetividade da fotografia. Como as tramas de uma rede, a imagem contemporânea sinaliza a negociação, a assimilação, e a refutação entre as diferentes formas de expressão, por exemplo, entre a fotografia, o cinema e as artes plásticas. É assim que o trabalho de Adam Magyar se distancia dos pressupostos modernos que buscaram compreender o tempo como uma sucessão de instantes fixos, e também do desejo concretizado pela fotografia moderna que capturar o instante como forma de eternizá-lo em uma imagem estática. Podemos dizer que suas imagens se inscrevem em uma 
concepção expandida ${ }^{13}$ de fotografia, que a partir do uso de tecnologias digitais abre novos diálogos com as outras mídias.

\section{Stainless - entre o estático e o movimento}

Historicamente, é preciso, sem dúvida, identificar os desvios em relação aos modelos hegemônicos de funcionamento dos dispositivos de produção de imagem - fotografia, cinema e vídeo - para ratificar uma série de experimentações com os dispositivos imagéticos, muitas delas recontextualizadas e repensadas, hoje, em torno das artes. Sabemos que os anos 1990 são marcados por novas formulações do fazer cinematográfico a partir de questões apresentadas por artistas, responsáveis pelo transporte do cinema para o campo das artes plásticas. O cinema, atravessado pela imagem eletrônica e numérica, exposto em museus e galerias de arte, permite importantes deslocamentos das funções predeterminadas de seu dispositivo hegemônico, bem como novos papéis para os observadores. Tais miscigenações parecem indicar a criação de um novo regime de visibilidade. No entanto, identificar as principais características desse novo regime implica uma revisão do estatuto da imagem, seja ela pictórica, fotográfica, cinematográfica ou videográfica, tendo em vista propostas que caminham menos na direção das especificidades e dos purismos identificados nas inúmeras estratégias e discursos da Modernidade, mas em direção à consolidação de um regime imagético em que os atravessamentos são constantemente privilegiados, bem como as relações que podemos estabelecer entre as imagens. "É entre as imagens que se efetuam cada vez mais as passagens, as contaminações, de seres e de regimes: por vezes nítidas, por vezes difíceis de serem circunscritas e, sobretudo, de serem nomeadas" (BELLOUR, 1993, p. 214).

Stainless (Figura 2) foi um trabalho desenvolvido por Adam Magyar entre 2011 e 2015, que tinha como objetivo registrar os trens nas plataformas de metrô de grandes cidades como Nova York, Paris e Tóquio. Utilizando câmeras adaptadas e aplicativos de correção de luz e distorções de formas, seu trabalho se insere em um contexto em que as imagens tornam-se híbridos de imagens estáticas e imagens em movimento. Sua abordagem inicial

130 termo "fotografia expandida" vem sendo utilizado por diversos pesquisadores para se referir à fotografia contemporânea como aquela capaz de ultrapassar os limites técnicos e conceituais da fotografia moderna. Segundo Fernandes Júnior (2006, p. 11): “Denominamos essa produção contemporânea mais arrojada, livre das amarras da fotografia convencional, de fotografia expandida, onde a ênfase está na importância do processo de criação e nos procedimentos utilizados pelo artista, para justificar a tese de que a fotografia também se expandiu em termos de flutuação ao redor da tríade peirciana (signo - ícone, índice e símbolo)." 
Figura 2: Stainless. \#7258. Nova York, 2010 (frame do vídeo)

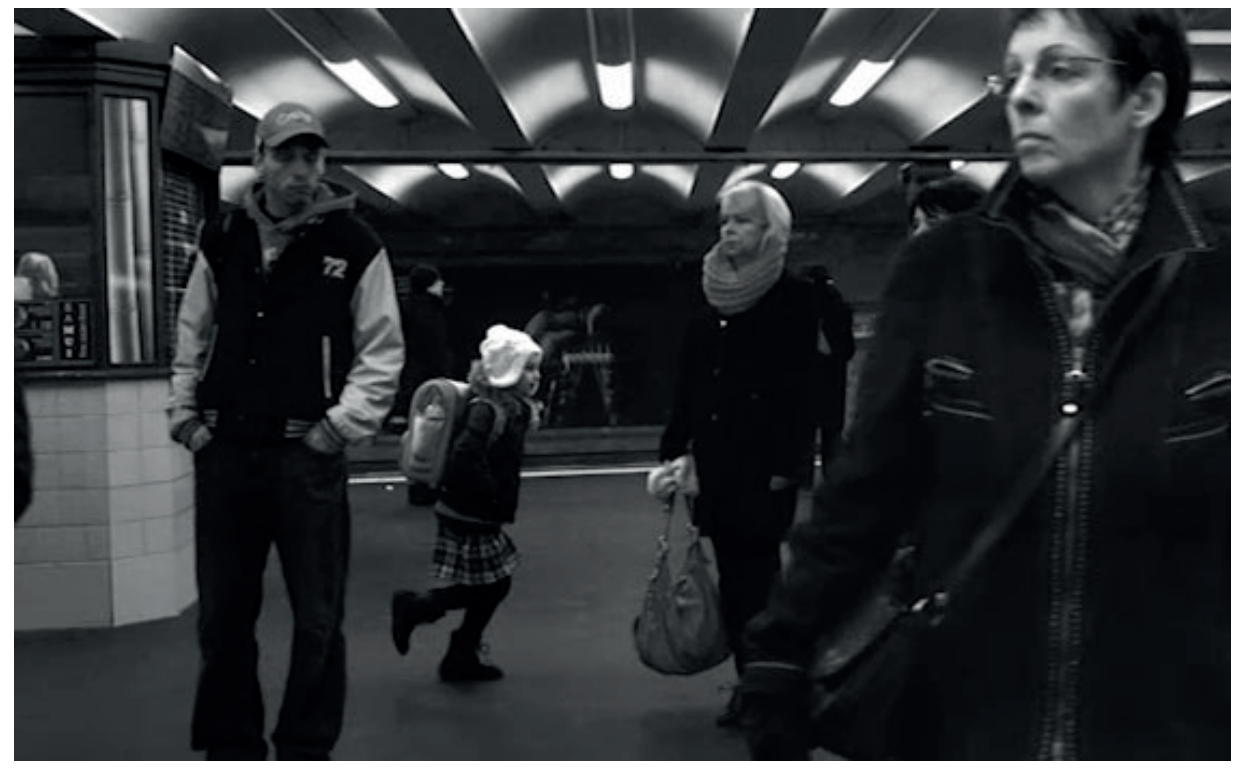

Fonte: Disponível em: <http://www.magyaradam.com/wp/?page_id=596>. Acesso em: 08 abr. 2020.

resultou em fotografias panorâmicas de alta definição, capazes de nos fazer ver aqueles instantes quaisquer, não pregnantes, vividos enquanto o trem passa pela plataforma. Imersos em pensamentos, distraídos com os próprios gadgets, estão os personagens urbanos capturados pelas lentes de Adam Magyar.

Com o intuito de registrar a passagem do tempo, e ao mesmo tempo enfatizar o fato de que coisas acontecem mesmo quando aparentemente nada está acontecendo, o artista inicia seus experimentos com o vídeo, utilizando uma câmera de alta velocidade adaptada para as suas necessidades. Usada inicialmente para testes com robótica e colisões de carros, a câmera de alta velocidade é capaz de obter 100.000 frames por segundo, viabilizando o antigo desejo de Marey na busca pelos microinstantes. A partir das adaptações realizadas no equipamento ao longo de dois anos, Magyar passa a produzir imagens de dentro dos trens, mudando seu referencial de trabalho, agora para o próprio movimento. Ao capturar as imagens em alta velocidade das pessoas nas plataformas e depois convertê-las em movimentos lentíssimos, Magyar constrói um complexo multitemporal, a partir do qual observamos os pequenos gestos do cotidiano. Os 12 segundos transcorridos ao longo da chegada do trem na plataforma são transformados em 12 minutos, evidenciando, através de um tempo ralentado, o que acontece durante o chamado "tempo perdido" da 
espera pelo trem. Sua intenção era criar uma imagem capaz de oferecer a experiência de um presente distendido, um agora contínuo, prenhe de temporalidades outras. Em entrevistas, o artista refere-se muitas vezes à sua busca por um tempo in between time, que poderia ser interpretado como um instante contínuo, bergsosiano, uma duração.

O longo travelling de Stainless revela uma plataforma cheia de gente aguardando a chegada do trem. A cena nos remete imediatamente a outras inúmeras imagens presentes na história da fotografia e do cinema nas quais as plataformas de trem e a situação de espera são privilegiadas. Desta vez, a cena se move, mas os personagens estão imóveis, ou se movimentando muito lentamente. Parecem nos dirigir o olhar, apesar de não haver qualquer relação deles com a nossa presença ou com a presença do artista. A cena guarda uma estranha imobilidade, na qual cada parcela da imagem parece constituir uma temporalidade própria. Tal estranhamento é acentuado pelo som de cada situação, seja este um burburinho de falas indiscerníveis ou algum fenômeno natural, como o vento, que se mistura ao som maquínico produzido pelo deslocamento do trem. Algo soa falso, e ao mesmo tempo convoca o nosso olhar para observar de forma privilegiada o que aconteceu ao longo daqueles 12 segundos. A forte sensação de descontinuidade, resultado da multiplicidade de tempos reunidos na mesma cena, é concomitante à experiência de um tempo contínuo e em fluxo, amplificado pelo efeito do longo travelling.

Ao mesmo tempo que o dispositivo construído por Magyar remete às propostas da fotografia moderna de rua, tudo indica que estamos sendo convidados a uma experiência visual diferente, capaz de promover uma oscilação em nossa crença da realidade através da imagem. Por um lado, estamos diante de uma imagem científica, que nos oferece uma realidade invisível à percepção humana: detalhes mínimos do movimento no espaço. Por outro, essa realidade ralentada nos transforma em observadores privilegiados que só podem observar a realidade a partir de um complexo múltiplo de tempo. Em oposição a uma concepção de tempo em continuidade tal qual formulada pela modernidade, Stainless oferece uma experiência do tempo baseada na simultaneidade de diferentes temporalidades. Trata-se agora de uma espacialização do tempo, onde os intervalos já não dividem o antes e o depois, pois são concebidos por instantes indivisíveis.

Se o tempo contínuo, infinito e quantificável foi para um grande número de pensadores um tempo irreal, responsável por graves enfermidades que impediam a experiência do tempo, então, segundo Agamben, a busca por outra 
temporalidade deve necessariamente basear-se na crítica do instante e do tempo contínuo (AGAMBEN, 2005). Ao reapresentar o problema do tempo perdido sob o viés de instantes contínuos, duracionais, o trabalho de Magyar busca pela possibilidade de uma experiência do tempo no cotidiano urbano que não seja a de um tempo em fuga. O tempo perdido de Magyar é o tempo dos pequenos gestos, das minúncias, dos instantes contínuos que nos passam desapercebidos, invisíveis na repetição e nas alienações do dia a dia. Esse tempo, uma vez tornado imagem, aparece como uma imagem estranha, sem unidade de tempo ou de espaço, e nos oferece uma forma singular de ver as multiplicidades do cotidiano. Não mais um real a ser revelado pela fotografia, mas um cotidiano a ser experimentado através da imagem.

A proposta da obra indica um deslocamento da fotografia em relação aos próprios discursos de verdade - a exemplo do panorama Stainless em que, ao invés de oferecer a imagem de uma totalidade, nos oferece um jogo entre real e ilusão, entre imobilidade e movimentos mínimos, instaurando assim temporalidades distintas. Trata-se também de deslocar o observador de um ambiente espacial e temporal organizado segundo regras lógicas, como as regras da perspectiva unilocular, para um observador lançado em um universo fragmentado e caótico, onde vigoram as dúvidas e as instabilidades. Deixamos as ancoragens dos pontos fixos e das definições e passamos a um estar "entre" que promove uma indecisão entre estar e não estar na imagem, entre ser e não ser autor ou espectador, entre estar parado ou em movimento, criando uma complexa temporalidade, elemento-chave dessas intrincadas desterritorializações. O "entre" ao qual nos referimos aqui não é um lugar geográfico ou topográfico intermediário a meio caminho entre um ponto e outro, mas um lugar híbrido, de mediações, capaz de tecer novas relações entre os elementos em questão. Aqui tempo e espaço combinam-se de outras maneiras, e permitem que a simultaneidade e a multiplicidade apareçam nas brechas do tempo dessas imagens. Sob essa perspectiva, a fotografia contemporânea, em diálogo com o cinema e o vídeo, torna-se elemento-chave da busca pelo cotidiano.

\section{Considerações finais}

A discussão em torno dos modos de representação do tempo mobilizou artistas e cientistas interessados na fotografia como técnica capaz de promover a captura de um tempo que hora é concebido como fluxo, hora é constituído de intervalos e intermitências. Em contraposição a toda uma história moderna da fotografia voltada para a captura dos instantes decisivos, Adam Magyar pauta suas intenções na busca por imagens capazes de nos oferecer instantes quaisquer em situações não extraordinárias, 
aparentemente sem importância, nas quais as pessoas não desempenham qualquer ação presumivelmente importante. Aqui, homens, mulheres e crianças aparecem imersos em seus pensamentos e gestos habituais como se experimentassem ao longo desses trajetos diários um mergulho numa temporalidade longa e profunda. Na perspectiva de Bergson (2006, p. 51), "Uma melodia que ouvimos de olhos fechados, pensando apenas nela, está muito perto de coincidir com esse tempo que é a própria fluidez de nossa vida interior", ainda que fosse preciso apagar as diferenças entre os sons para que pudéssemos conservar apenas a continuação do precedente no que vai sucedê-lo para alcançar o que ele chamou de tempo fundamental. Nessa sucessão indivisível, nessa transição ininterrupta, Magyar vai buscar a própria concepção de continuidade e de fluxo através de imagens que correspondem as ações cotidianas, onde o fotografado/filmado está sempre alheio à presença de uma câmera.

Sua obsessão pelo "tempo perdido" o aproxima das experiências de Marey, mas também se afasta delas ao crer no tempo como continuidade indivisível. O tempo perdido de Magyar é o tempo não percebido dos trajetos rotineiros, das caminhadas cotidianas, dos deslocamentos diários. Um tempo em continuidade que não se pode capturar através da fotografia instantânea sob a pena de imediatamente perdê-lo. Utilizando-se de câmeras e softwares por ele construídos, o artista sai em busca de imagens que nos permitam experimentar esse tempo distendido, porém simultâneo, múltiplo, chamado por Bergson de tempo puro.

Entre a marcha de Stainless e a espera de Urban Flow, Adam Magyar nos oferece uma temporalidade distendida, marcada pela multiplicidade. Se em Urban Flow a câmera transpõe os fluxos da cidade para uma fotografia panorâmica construída artificialmente, em Stainless a horizontalidade do travelling dá a ver os gestos da espera através dos movimentos mínimos da paisagem fugidia da plataforma de trem. No primeiro trabalho, a câmera está parada e a cidade em movimento, e o resultado é uma fotografia cheia de invisíveis, porém prenhe de tempos. No segundo, a cena da espera ganha movimentos lentíssimos, ainda que distribuídos de forma variável e dissimétrica dentro do longo frame. Dessa forma, o trabalho de Magyar busca não a representação do tempo no espaço, mas as múltiplas formas a partir das quais o tempo emerge em uma imagem, seja ela estática ou em movimento. Suas estratégias operam por desaceleração do movimento e por distensão do instante, para nos fazer ver a multiplicidade e a simultaneidade de tempos presentes em cada imagem. O tempo perdido moderno torna-se agora um tempo bifurcado, paradoxal 
no qual a imagem deixa de ser o rastro de um espaço percorrido para tornar-se ela mesma expressão do tempo. As cenas criadas são realidades paradoxais e indiscerníveis, fora de uma lógica temporal linear e sucessiva, e que talvez possam funcionar como sintomas de outra forma de pensar o tempo no contexto atual, uma temporalidade típica alcançada apenas a partir da imagem fotocinemática, híbrida, na contemporaneidade.

\section{Referências}

AGAMBEN, Giorgio. Infância e história: destruição da experiência e origem da história. Belo Horizonte: Editora UFMG, 2005.

BELLOUR, Raymond. Entre-imagens. São Paulo: Papirus, 1997.

BENJAMIN, Walter. Magia e técnica: arte e política. São Paulo: Brasiliense, 1994. (Obras Escolhidas, v. I.).

BERGSON, Henri. Matéria e memória.

São Paulo: Martins Fontes, 1999. . A natureza do tempo. In:

Duração e simultaneidade. São Paulo: Martins Fontes, 2006.

BRAUM, Marte. Picturing Time: The Work of Etienne-Jules Marey (1830-1904). Chicago: Chicago Press, 1992.

BUCI-GLUCKSMANN, Christine. Esthétique de l'éphémère. Paris: Galilée, 2003.

CRARY, Jonathan. Técnicas do observador: visão e modernidade no século XIX. Rio de Janeiro: Contraponto, 2012.
DOANE, Mary Ann. The Emergence of the Cinematic Time: modernity, contingency, the archive. Massachusetts: Harvard University Press, 2002.

DOBAL, Susana. Tempo fotográfico e tempo cinematográfico: reciprocidade In: FATORELLI, Antonio; CARVALHO,Victa; PIMENTEL, Leandro. (Org). Fotografia Contemporânea: desafios e tendências. Rio de Janeiro: Mauad, 2016. p. 79-92.

FABRIS, Annateresa. O desafio do olhar: fotografia e artes visuais no período das vanguardas históricas. São Paulo: Martins Fontes, 2011.

\section{FATORELLI, Antonio. Fotografia}

contemporânea: entre o cinema, o vídeo e as novas mídias. Rio de Janeiro: Senac, 2013.

FERNANDES JÚNIOR, Rubens. Processos de criação na fotografia: apontamentos para o entendimento de vetores e das variáveis da produção fotográfica. Revista FACOM, n. 16, p. 10-19, 2006.

\section{GUNTHERT, André. La Conquête de} l'instantané. L’archéologie de l'imaginaire photographique em France (1841-1895). PART 1. 1999. Thèse (Doctorat). Disponível em: <https://tel.archives-ouvertes.fr/ halshs-00004607/file/these-Gunthert-part1. pdf>. Acesso em: 02 jul. 2018.

HAMMER, Joshua. Einstein's Camera: How One Renegade Photographer is Hacking the Concept of Time. 2014. Disponível em: $<$ https://medium.com/matter/einsteinscamera-88aa8a185898>. Acesso em: 02 jul. 2018.

HIGHMORE, Ben. Everyday Life and Cultural Theory. Nova York: Routledge, 2010. 
SANZ, Claudia. Entre o tempo perdido

e o instante: cronofotografia, ciência e

temporalidade moderna. Boletim do Museu

Paraense Emílio Goeldi, Belém, v. 9, n. 2,

p. 443-462, maio/ ago. 2014.

SCOTT, Clive. Street Photography: From Atget

to Cartier-Bresson. Nova York: I. B. Tauris \&

Co, 2009.

SIMMEL. George. As grandes cidades e a vida do espírito. MANA: Estudos de Antropologia

Social, v. 11, n. 2, p. 577-591, 2005.

SHERINGHAN, Michael. Everyday Life: Theories and Practices From Surrealism to the Present.

Nova York: Oxford University Press, 2009.

Informações sobre 0 artigo

Resultado de projeto de pesquisa: 0 cotidiano na arte contemporânea: entre o ver e o habitar a imagem.

Fontes de financiamento: APQ1/FAPERJ - proc: E-26/010.001565/2019.

Considerações éticas: Não se aplica.

Declaração de conflito de interesses: Não se aplica.

Apresentação anterior: Compós 2019, Porto Alegre. A primeira versão deste artigo foi apresentada no Grupo de Trabalho Cinema, Fotografia e Audiovisual do XXVIII Encontro Anual da Compós, 2019.

Agradecimentos/Contribuições adicionais: Não se aplica. 


\section{Lost Time: the invisible everyday life in the work of Adam Magyar}

\section{Tiempo perdido: el cotidiano} invisible en la obra de Adán Magyar

\section{Abstract:}

In search of forms of time representation able to demonstrate its complexity, several recent visual and audiovisual works of art turn to urban daily life as a strategy to reflect on our current experience. From the Urban Flow (2006-2013) and Stainless (2011-2015) series by the Hungarian artist Adam Magyar, this article intends to observe emerging temporalities seized through hybrid technologies to capture images in the context of cities. Our objective is to reflect on the multiple ways of experiencing time through images today, Modern lost time becomes, in Magyar's work, a paradoxical time in which the image ceases to be the trail of a traveled space to become an expression of time itself.

\section{Keywords:}

Photography. Everyday life. Time. Experience.

\section{Victa de Carvalho Pereira da Silva}

Doutora pelo Programa de Pós-Graduação em Comunicação da Universidade Federal do Rio de Janeiro, com estágio de pesquisa na Université Paris1: Sorbonne, Paris, França. Professora Associada da Escola de Comunicação da Universidade Federal do Rio de Janeiro, onde é também professora e vice-coordenadora do Programa de Pós-Graduação em Comunicação e Cultura da Escola de Comunicação da UFRJ. É integrante o grupo de pesquisa $\mathrm{N}$-imagem e vice-coordenadora do grupo de pesquisa Fotografia, Imagem e Pensamento (CNPq). Universidade Federal do Rio de Janeiro, Rio de Janeiro, Rio de Janeiro, Brasil.

\section{Resumen:}

En busca de formas de representación del tiempo capaces de demostrar su complejidad, varias obras visuales y audiovisuales recientes se centran en la vida cotidiana urbana como una estrategia para reflexionar sobre nuestra experiencia actual. De las series Urban Flow (2006-2013) y Stainless (2011-2015) del artista húngaro Adam Magyar, este artículo pretende observar las temporalidades emergentes incautadas a través de tecnologías de captura de imágenes híbridas en el contexto de ciudades Nuestro objetivo es reflexionar sobre las múltiples formas de experimentar el tiempo a través de las imágenes actuales. El tiempo perdido moderno se convierte, en el trabajo de Magyar, en un tiempo paradójico en el que la imagen deja de ser el rastro de un espacio recorrido para convertirse en una expresión del tiempo mismo.

Palabras clave:

Fotografía. Cotidiano. Tiempo. Experiencia. 